\title{
Knowledge on Stroke Warning Signs and Associated Factors Among Hypertensive Patients, Northwest Ethiopia: An Institution-Based Cross-Sectional Study
}

\author{
Adane Birhanu Nigat (D) \\ Moges Wubneh Abate (iD) \\ Agimasie Tigabu Demelash ' \\ Nigusie Selomon Tibebu (iD ${ }^{2}$ \\ Chalie Marew Tiruneh (iD ${ }^{2}$ \\ Tigabu Desie Emiru (D ${ }^{2}$ \\ Mehd Abdu Yimam (D) ${ }^{3}$ \\ Abebe Dires Nega (D) ${ }^{4}$ \\ Yohannes Shumet Yimer (iD ${ }^{5}$ \\ 'Department of Adult Health Nursing, \\ College of Health Sciences, Debre Tabor \\ University, Debre Tabor, Ethiopia; \\ ${ }^{2}$ Department of Pediatrics and Child \\ Health Nursing, College of Health \\ Sciences, Debre Tabor University, Debre \\ Tabor, Ethiopia; ${ }^{3}$ Department of Nursing, \\ College of Medicine and Health Sciences, \\ Mizan-Tepi University, Mizan Teferi, \\ Ethiopia; ${ }^{4}$ Department of Comprehensive \\ Nursing, College of Medicine and Health \\ Sciences, Wollo University, Dessie, \\ Ethiopia; ${ }^{5}$ Department of Pharmacy, \\ College of Health Sciences, Debre Tabor \\ University, Debre Tabor, Ethiopia
}

Introduction: Stroke is one of the leading causes of death globally and is a major cause of disability worldwide. It is a preventable and treatable disease by the prevention of modifiable risk factors and early recognition of warning signs, respectively.

Objective: To assess knowledge on stroke warning signs and associated factors among hypertensive patients at South Gondar Zone Comprehensive Specialized Hospital, Northwest Ethiopia, 2020.

Methods: An institution-based cross-sectional study was conducted in South Gondar Zone Comprehensive Specialized Hospital from June 1-30, 2020. A systematic random sampling technique was used and data were collected through face to face interviews. Data were entered into Epi data version 4.6.0.0 and exported to SPSS version 25 for cleaning and analysis. Bivariate and multivariable logistic regression analysis was used and variables with $\mathrm{p}<0.05$ in the multivariable analysis were considered as statistically significant.

Results: Two hundred and fifty-three hypertensive patients completed the questionnaire with a response rate of $100 \%$. Among the total respondents, $15 \%$ (95\% CI: $10.7,19.4)$ of participants had good knowledge of stroke warning signs. Younger age (AOR: 2.82; 95\% CI: 1.18, 6.74), urban residence (AOR: 2.9; 95\% CI: 1.04, 8.11), being educated (AOR: 2.6; 95\% CI: $1.09,6.23$ ) and having long duration hypertension follow up (AOR: $2.7 ; 95 \% \mathrm{CI}$ : $1.25,5.81)$ were significantly associated with good knowledge of stroke warning signs.

Conclusion: This study revealed that participants had poor knowledge of stroke warning signs. Younger age, urban residence, being educated and having long duration hypertension follow up were predictors of good stroke warning signs knowledge. Health information dissemination needs to be strengthened for hypertensive patients, particularly for older, rural residents, the non-educated and those having short duration of hypertension follow up.

Keywords: hypertension, knowledge, stroke, warning signs, Ethiopia

\section{Introduction}

Stroke is one of the leading causes of death globally and is a major cause of disability worldwide. About $70 \%$ of strokes and $87 \%$ of both stroke-related deaths and disabilities occur in low- and middle-income countries. ${ }^{1}$ It is a preventable and treatable disease by the prevention of modifiable risk factors and early recognition of warning signs, respectively. ${ }^{2}$ People with hypertension are four times more likely to have a stroke than those with normal blood pressure. ${ }^{3}$ Hypertension (HTN) is the most common modifiable risk factor for stroke, with blood pressure (BP) reduction being associated with a reduced rate of stroke recurrence. ${ }^{4}$ About $80 \%$ of people who have their first stroke have high blood pressure. ${ }^{5}$
Correspondence: Adane Birhanu Nigat Department of Adult Health Nursing, College of Health Sciences, Debre Tabor University, Debre Tabor, Ethiopia Email adanebirhanu23@gmail.com 
Stroke is an enormous financial burden not only for patients but also for society as a whole by placing a great demand on family members and caregivers. Therefore, public stroke knowledge is the key point in stroke prevention. ${ }^{6}$

A study conducted in Turkey and Pakistan among hypertensive patients revealed that the knowledge of stroke warning signs was poor. ${ }^{7,8}$ Whereas studies conducted in Nepal, Saudi Arabia, and two settings in Nigeria showed that the knowledge of hypertensive patients was good. ${ }^{9-12}$ Another study conducted in Ethiopia among hypertensive patients showed the knowledge of participants regarding stroke warning signs was poor. ${ }^{13}$

Even though the burden of stroke in Ethiopia is increasing over time, there is limited research showing the knowledge of stroke warning signs among patients with hypertension. Therefore, to prevent the occurrence of stroke and its burden, assessing the knowledge of hypertensive patients about warning signs of stroke is crucial. So this study intended to assess knowledge on stroke warning signs and associated factors among hypertensive patients at South Gondar Zone Comprehensive Specialized Hospital, Northwest Ethiopia.

\section{Methods}

\section{Study Design, Setting and Period}

An institution-based cross-sectional study design was used at the chronic follow up clinic of South Gondar Zone Comprehensive Specialized Hospital from June 1-30, 2020.

\section{Source Population}

All hypertensive patients who had to follow up at SGCSH chronic illness follow up clinic.

\section{Study Population}

All hypertensive patients who came during the data collection period.

\section{Inclusion Criteria}

All hypertensive patients who were aged $>18$ years.

\section{Exclusion Criteria}

All hypertensive patients who were seriously ill and who would not able to give information.

\section{Sample Size Determination}

The size of participants that were recruited in the study was estimated by using a single population proportion formula by considering the proportion of participants having good knowledge as $18.3 \%$ which was taken from the previous study conducted at Bahir Dar, ${ }^{13}$ a confidence level of $95 \%$ and margin of error of $5 \%$ to get the maximum sample size.

$$
\mathrm{n}=\mathrm{Z}(\alpha / 2)^{2} \mathrm{p}(1-\mathrm{p})
$$

$\mathrm{d}^{2}$

Where:

$\mathrm{n}-$ is the estimated sample size,

$\mathrm{p}$ - is the proportion of patients who had good knowledge of stroke warning signs,

$\mathrm{d}-$ is the margin of error.

Then, $\mathrm{n}=(1.96)^{2} * 0.183(1-0.183)=230$

$(0.05)^{2}$

Then by adding $10 \%$ non-response rate the final sample size was 253 .

Finally, from the calculated sample size the number of participants that had been recruited in the study was 253 which was the highest among the calculated samples.

\section{Dependent Variables}

Knowledge of stroke warning signs.

\section{Independent Variables}

Socio-demographic characteristics (age, sex, religion, residence, occupational status, educational status, marital status, income status).

Clinical and behavioral factors (duration of hypertension, previous history of stroke, family history of stroke, having DM, living with HIV/AIDS, alcoholism, chat chewing and cigarette smoking).

\section{Operational Definition}

Knowledge on stroke warning signs: was assessed by requesting the participants to respond to 10 stroke warning signs questions. Each correct answer was recorded as 1, and an incorrect answer recorded as 0. The mean (4.01) value of the answers was considered to categorize the participants as having good and poor stroke warning signs knowledge.

Good knowledge of stroke warning signs included those participants who had responded to the mean value and above of stroke warning signs knowledge questions. ${ }^{10}$ 


\section{Sampling Methods and Procedures}

The study was conducted at SGCSH chronic illness follow up clinic by using a systematic random sampling technique. To select the study participants, the estimated number of hypertensive patients in the data collection period was calculated first. So, the average number of hypertensive patients that can be seen in the data collection period was 856. Then, to determine the interval ( $\mathrm{k}$ - value) this average number was divided by the calculated sample size and participants were selected with every 3 intervals. The first participant was selected by using lottery method; this was the first hypertensive patient who came first in the follow-up clinic during the first day of data collection.

\section{Data Collection Techniques and Tools}

A structured closed-ended questionnaire that has been adopted from previous studies ${ }^{10,13-15}$ was used and data were collected through face to face interviews. Face validity was checked by three academic opinions (one Assistant Professor and two Lecturers).

The questionnaire comprises four parts: part I, sociodemographic factors; part II, clinical and behavioral factors; part III, stroke information sources and risk factors of stroke; and part IV, hypertensive patient's knowledge on stroke warning signs. Three data collectors (BSc nurses) and one supervisor (MSc nurse) participated in the data collection.

\section{Data Quality Control Measures}

Both the data collectors and the supervisor were trained for one day on the objective, methodology and data collection approach of the research. All the questionnaires were prepared in English and translated to the Amharic language then back-translated to English by two senior academics from English language and Adult Health Nursing departments to check its consistency. Pre-test was conducted on $5 \%{ }^{13}$ of the samples at Mekane Eyesus Primary Hospital to see the consistency and applicability of the instrument. Also, the reliability of the tool was tested with Cronbach alpha coefficient and it was 0.706 .

Finally, data were checked for completeness before entry to computer software for analysis.

\section{Data Processing and Analysis}

Data were entered and coded in to Epi data version 4.6.0.0 and exported to SPSS version 25.0 for cleaning and analysis. Descriptive statistics was computed and the results have described in percentage and frequency using tables and figures. Bivariate and multivariable logistic regression analysis was done to show association of independent variables with knowledge on stroke warning signs. Associations between independent variables and dependent variable were analyzed first using bivariate logistic regression analysis to identify factors which are associated with the outcome variable. Then, those variables with a significance level (p-value) of $<0.2$ in the bivariate analysis were entered into multivariable analysis. Model fitness was checked through Hosmer-Lemeshow goodness of fit test and it was fitted. In multivariable analysis, the association between independent variables with the outcome variable was measured using adjusted odds ratios, $95 \%$ confidence interval (CI) and $\mathrm{p}$ values of less than or equal to 0.05 was considered as statistically significant.

\section{Results}

\section{Socio-Demographic Characteristics of Study Participants}

Two hundred and fifty-three hypertensive patients were recruited for the study with a response rate of $100 \%$. Among the respondents, $65.6 \%$ of them were male patients. The mean age of participants were 56.7 with S.D. \pm 8.9 years. Majority of the participants $(87.7 \%)$ were orthodox Christians. Most (66\%) of the respondents were urban residents and $83.8 \%$ of them were married. Approximately $56.5 \%$ of the respondents were educated and the majority $(30.8 \%)$ of them were merchants (Table 1$)$.

\section{Clinical and Behavioral Factors}

One hundred and seventy-one $(67.6 \%)$ of the participants were diagnosed with hypertension in the past 5 years. Most (98.8\%) of the respondents had no previous history of stroke. Moreover, 19 (7.5\%) of the respondents had a family history of stroke and $4.3 \%$ of them had diabetes mellitus concomitantly. About $24.5 \%$ of the participants chew chat and drink alcohol, and $13 \%$ of them smoke cigarettes (Table 2).

\section{Stroke Information Sources of Respondents}

The majority (91\%) of the respondents had heard stroke information from health-care professionals, followed by television (34\%) and radio (19\%) as the second and third sources of stroke information. Only $9 \%$ of hypertensive patients had received stroke information from their friends (Figure 1). 
Table I Socio-Demographic Characteristics of Respondents at South Gondar Zone Comprehensive Specialized Hospital, Northwest Ethiopia, from June I-30, 2020 ( $n=253$ )

\begin{tabular}{|c|c|c|c|}
\hline Variables & Category & Frequency & $\begin{array}{c}\text { Percent } \\
(\%)\end{array}$ \\
\hline \multirow[t]{2}{*}{ Sex } & Male & 166 & 65.6 \\
\hline & Female & 87 & 34.4 \\
\hline \multirow[t]{2}{*}{ Age } & $<45$ & 44 & 17.4 \\
\hline & $>45$ & 209 & 82.6 \\
\hline \multirow[t]{2}{*}{ Residence } & Urban & 167 & 66.0 \\
\hline & Rural & 86 & 34.0 \\
\hline \multirow[t]{2}{*}{ Religion } & Orthodox & 222 & 87.7 \\
\hline & Muslim & 31 & 12.3 \\
\hline \multirow[t]{2}{*}{$\begin{array}{l}\text { Educational } \\
\text { status }\end{array}$} & $\begin{array}{c}\text { Unable to read and } \\
\text { write }\end{array}$ & 110 & 43.5 \\
\hline & Educated & 143 & 56.5 \\
\hline \multirow[t]{3}{*}{ Marital status } & Single & 15 & 5.9 \\
\hline & Married & 212 & 83.8 \\
\hline & Widowed & 26 & 10.3 \\
\hline \multirow{7}{*}{$\begin{array}{l}\text { Occupational } \\
\text { status }\end{array}$} & Government worker & 70 & 27.7 \\
\hline & Merchant & 78 & 30.8 \\
\hline & Farmer & 67 & 26.5 \\
\hline & Housewife & 23 & 9.1 \\
\hline & Retired & 10 & 4.0 \\
\hline & Labor worker & 3 & 1.2 \\
\hline & Student & 2 & 0.8 \\
\hline \multirow[t]{2}{*}{ Income status } & $<5000$ ETB & 186 & 73.5 \\
\hline & $>5000$ ETB & 67 & 26.5 \\
\hline
\end{tabular}

\section{Risk Factors of Stroke Responded by}

\section{Participants}

About $96.8 \%$ of the respondents identified high blood pressure as the risk factor for stroke. Heart disease (64\%), excessive alcohol consumption (62.5\%), smoking (60.5\%), diabetes mellitus (58.1\%), obesity (32.4\%), and physical/emotional stress $(26.9 \%)$ were also under the highly responded risk factors by the participants. The least identified risk factor by the respondents was sexual intercourse (2\%) (Table 3$)$.

\section{Stroke Warning Signs Questions Responded by Participants}

Sudden difficulty in swallowing (80.6\%), sudden loss of memory $(78.3 \%)$, and sudden difficulty in speaking (76.7\%) were the major warning signs identified by the participants. Sudden onset of severe headache (33.6\%) was the least warning sign which was identified by the respondents (Table 4).
Table 2 Clinical and Behavioral Factors of Respondents at South Gondar Zone Comprehensive Specialized Hospital, Northwest Ethiopia, from June I-30, $2020(n=253)$

\begin{tabular}{|c|c|c|c|}
\hline Variables & Category & Frequency & Percent (\%) \\
\hline \multirow{2}{*}{$\begin{array}{l}\text { Duration of } \\
\text { hypertension }\end{array}$} & $<5$ years & $17 \mid$ & 67.6 \\
\hline & $>5$ years & 82 & 32.4 \\
\hline \multirow{2}{*}{$\begin{array}{l}\text { Previous history of } \\
\text { stroke }\end{array}$} & Yes & 3 & 1.2 \\
\hline & No & 250 & 98.8 \\
\hline \multirow[t]{2}{*}{ Family history of stroke } & Yes & 19 & 7.5 \\
\hline & No & 234 & 92.5 \\
\hline \multirow{2}{*}{$\begin{array}{l}\text { Having diabetes } \\
\text { mellitus }\end{array}$} & Yes & 11 & 4.3 \\
\hline & No & 242 & 95.7 \\
\hline \multirow[t]{2}{*}{ Living with HIVIAIDS } & Yes & 44 & 17.4 \\
\hline & No & 209 & 82.6 \\
\hline \multirow[t]{2}{*}{ Chat chewing } & Yes & 62 & 24.5 \\
\hline & No & 191 & 75.5 \\
\hline \multirow[t]{2}{*}{ Cigarette smoking } & Yes & 33 & 13.0 \\
\hline & No & 220 & 87.0 \\
\hline \multirow[t]{2}{*}{ Alcoholism } & Yes & 62 & 24.5 \\
\hline & No & 191 & 75.5 \\
\hline
\end{tabular}

\section{Knowledge of Respondents on Stroke Warning Signs}

Among the total study participants, only $15 \%$ of them had good knowledge and the remaining $85 \%$ had poor knowledge on stroke warning signs (Figure 2).

\section{Factors Associated with Knowledge on Stroke Warning Signs}

To identify factors associated with knowledge of stroke warning signs among patients with hypertension, bivariate logistic regression analysis was done. On this analysis, age, residence, educational status, duration of hypertension, family history of stroke, having diabetes mellitus comorbidity, living with HIV/AIDS and alcoholism were the significant variables associated with knowledge of stroke warning signs.

In multivariable logistic regression analysis, younger patients were 2.8 times more likely to had good stroke warning signs knowledge compared with older individuals (AOR: 2.82; 95\% CI: 1.18, 6.74).

Urban residents were 2.9 times higher than patients from a rural area to have good stroke warning signs knowledge (AOR: 2.9; 95\% CI: 1.04, 8.11).

Hypertensive patients who are educated were 2.6 times more likely to have good stroke warning sign knowledge 


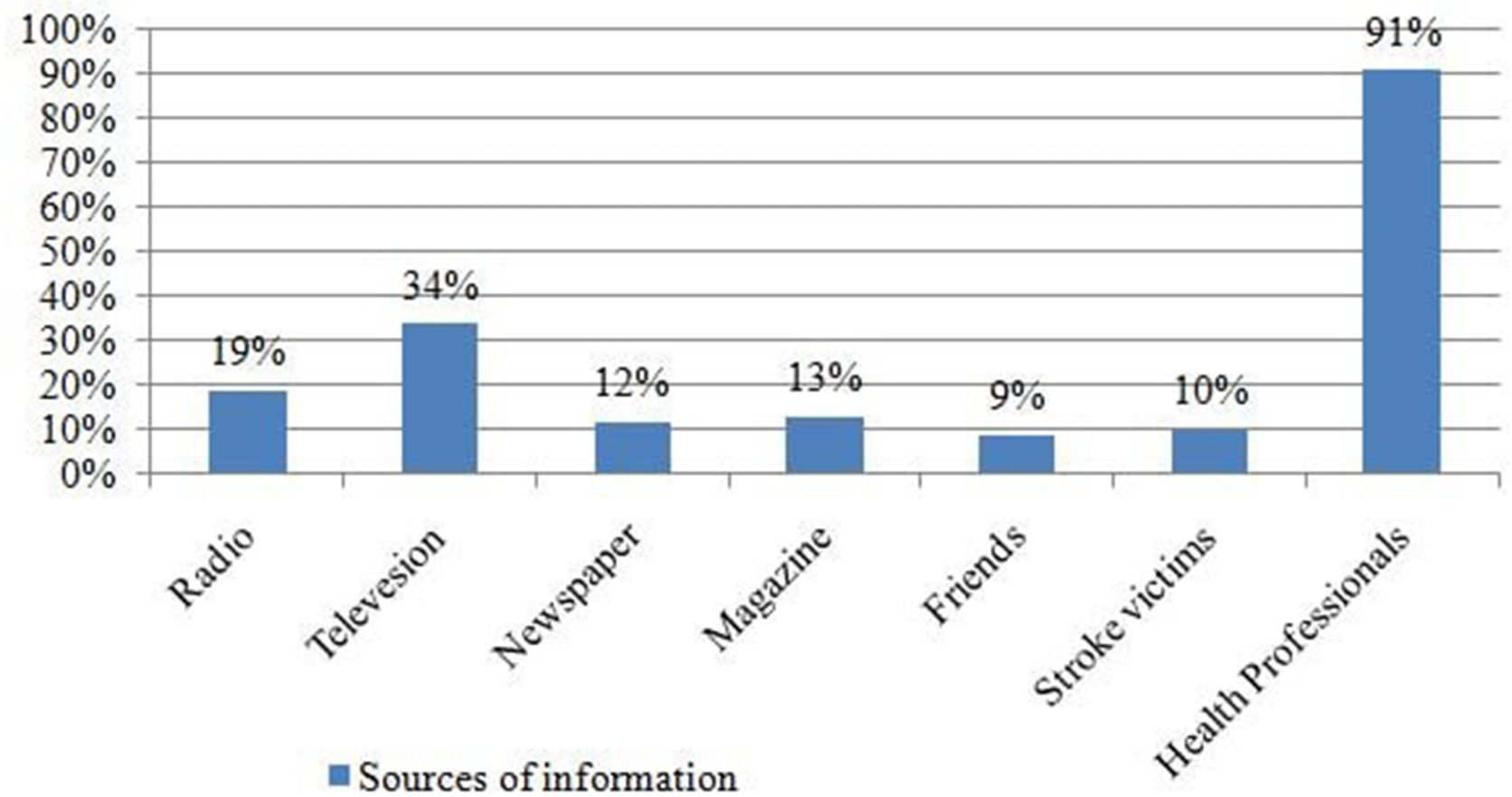

Figure I Stroke information sources of respondents at South Gondar Zone Comprehensive Specialized Hospital, Northwest Ethiopia, from June 0 I to 30 , 2020 ( $\mathrm{n}=253$ ).

compared with those non-educated patients (AOR: 2.6; 95\% CI: 1.09, 6.23).

Patients that had been diagnosed with hypertension 5 years ago were 2.7 times more likely to have good stroke warning symptoms knowledge compared with those who had been diagnosed within the past 5 years (AOR: 2.7; $95 \%$ CI: $1.25,5.81$ ) with a p-value of $<0.05$ (Table 5 ).

\section{Discussion}

Worldwide, stroke is one of the leading causes of death and disability. Moreover, it is a major cause of death with hypertension being identified as an important modifiable risk factor.

Hypertensive patients are at high risk of developing stroke and suffering from its consequences. Knowledge of hypertensive patients on warning signs of stroke is essential to prevent stroke morbidity and mortality.

In this study, $15 \%(95 \% \mathrm{CI}: 10.7,19.4)$ of the participants had good knowledge about stroke warning signs. This was lower than the study conducted at Felege Hiwot Referral Hospital of Bahir Dar. ${ }^{13}$ This difference might be due to differences in institutional awareness creation for the target group as well as a better living standard of the target groups to access information at Felege Hiwot study.

However, it is lower than studies conducted in two settings in Nigeria (Benin and Sokoto), Saudi Arabia, Nepal and Pakistan. ${ }^{7,9-11}$ Despite this, the study was higher than the study conducted in Iraq. ${ }^{2}$ This discrepancy might be due to differences in socio-economic, sociodemographic factors, the difference in sample size and accessibility of health-care delivery systems of those countries.

In this study age was a significant predictor of good knowledge of stroke warning signs; the odds of good stroke warning signs knowledge were 2.8 times higher in younger age patients than older age. This is consistent with studies reported from Bahir Dar and Nigeria in which older age was associated with poor warning signs knowledge. ${ }^{11,13}$ This might be due to the fact that younger patients are highly active in joining technological advancements to access information regarding to stroke warning signs.

However, it contradicts the study done in Turkey that older age was associated with good stroke warning signs knowledge. ${ }^{8}$ This might be due to the reason that older patients have long-term experience with the problem which allows them to have more information access throughout the duration, since it is more common in older individuals.

The odds of good stroke warning signs knowledge were 2.9 times higher in urban residents than those from rural areas. This is consistent with the study done at Bahir Dar. ${ }^{13}$ This might be due to the fact that patients from urban areas had more information access about stroke than rural residents.

Educational status was the significant variable that affected knowledge of stroke warning signs; showing 
Table 3 Risk Factors of Stroke Responded by Participants at South Gondar Zone Comprehensive Specialized Hospital, Northwest Ethiopia, from June I-30, 2020 ( $n=253)$

\begin{tabular}{|c|c|c|c|}
\hline Variables & Category & Frequency & Percent \\
\hline \multirow[t]{2}{*}{ High BP } & Yes & 245 & 96.8 \\
\hline & No & 8 & 3.2 \\
\hline \multirow[t]{2}{*}{ Diabetes mellitus } & Yes & 147 & 58.1 \\
\hline & No & 106 & 41.9 \\
\hline \multirow[t]{2}{*}{ Heart disease } & Yes & 162 & 64.0 \\
\hline & No & 91 & 36.0 \\
\hline \multirow[t]{2}{*}{ Abnormal blood cholesterol level } & Yes & 30 & 11.9 \\
\hline & No & 223 & 88.1 \\
\hline \multirow[t]{2}{*}{ Unhealthy diet/excess fat in the diet } & Yes & 52 & 20.6 \\
\hline & No & 201 & 79.4 \\
\hline \multirow[t]{2}{*}{ Smoking } & Yes & 153 & 60.5 \\
\hline & No & 100 & 39.5 \\
\hline \multirow[t]{2}{*}{ Obesity } & Yes & 82 & 32.4 \\
\hline & No & 171 & 67.6 \\
\hline \multirow[t]{2}{*}{ Drinking excessive alcohol } & Yes & 158 & 62.5 \\
\hline & No & 95 & 37.5 \\
\hline \multirow[t]{2}{*}{ Physical/emotional stress } & Yes & 68 & 26.9 \\
\hline & No & 185 & 73.1 \\
\hline \multirow[t]{2}{*}{ Sedentary lifestyle } & Yes & 39 & 15.4 \\
\hline & No & 214 & 84.6 \\
\hline \multirow[t]{2}{*}{ Sexual intercourse } & Yes & 5 & 2.0 \\
\hline & No & 248 & 98.0 \\
\hline \multirow[t]{2}{*}{ Sudden exposure to cold weather } & Yes & 61 & 24.1 \\
\hline & No & 192 & 75.9 \\
\hline
\end{tabular}

that the odds of good stroke warning sign knowledge was 2.6 times higher in those patients who are educated compared with individuals who were not educated. This is consistent with studies conducted in Ethiopia, Nigeria, Saudi Arabia, Turkey, and Spain. ${ }^{2,8,10,12,13,16}$ This might be due to the reason that educated individuals have easy access for stroke-related information due to better interaction with the community and access to different medias such as magazines and internet. In addition, the way they access and understand health information is better in those educated individuals than non-educated ones.

Duration of hypertension was another significant predictor of good stroke warning signs knowledge. The odds of good stroke warning signs knowledge was 2.7 times higher in those who were diagnosed to have hypertension 5 years ago than those who were diagnosed with hypertension within the past 5 years. This is similar to a study conducted
Table 4 Stroke Warning Signs Questions Responded by Respondents at South Gondar Zone Comprehensive Specialized Hospital, Northwest Ethiopia, from June I-30, 2020 $(n=253)$

\begin{tabular}{|l|c|c|c|}
\hline Variables & Category & $\begin{array}{c}\text { Frequency } \\
\text { (N) }\end{array}$ & $\begin{array}{c}\text { Percent } \\
\text { (\%) }\end{array}$ \\
\hline Sudden onset of severe headache & Yes & 85 & 33.6 \\
& No & 168 & 66.4 \\
\hline Sudden dizziness or loss of balance & Yes & 163 & 64.4 \\
or coordination & No & 90 & 35.6 \\
\hline Sudden loss of memory & Yes & 198 & 78.3 \\
& No & 55 & 21.7 \\
\hline Sudden loss of vision & Yes & 121 & 47.8 \\
& No & 132 & 52.2 \\
\hline Sudden difficulty in speaking & Yes & 194 & 76.7 \\
& No & 59 & 23.3 \\
\hline Sudden difficulty in swallowing & Yes & 204 & 80.6 \\
& No & 49 & 19.4 \\
\hline Sudden loss or reduced sensation & Yes & 154 & 60.9 \\
on one side of the body & No & 99 & 39.1 \\
\hline Sudden loss or reduced sensation & Yes & 146 & 57.7 \\
all over the body & No & 107 & 42.3 \\
\hline Sudden weakness or paralysis on & Yes & 126 & 49.8 \\
one side of the body & No & 127 & 50.2 \\
\hline Sudden weakness or paralysis all & Yes & 125 & 49.4 \\
over the body & No & 128 & 50.6 \\
\hline
\end{tabular}

in Iraq. ${ }^{2}$ This might be because having long adherence for the problem results in redundant access of information from the clinicians and seeking attention for the problem after the diagnosis resulting in further searches for information.

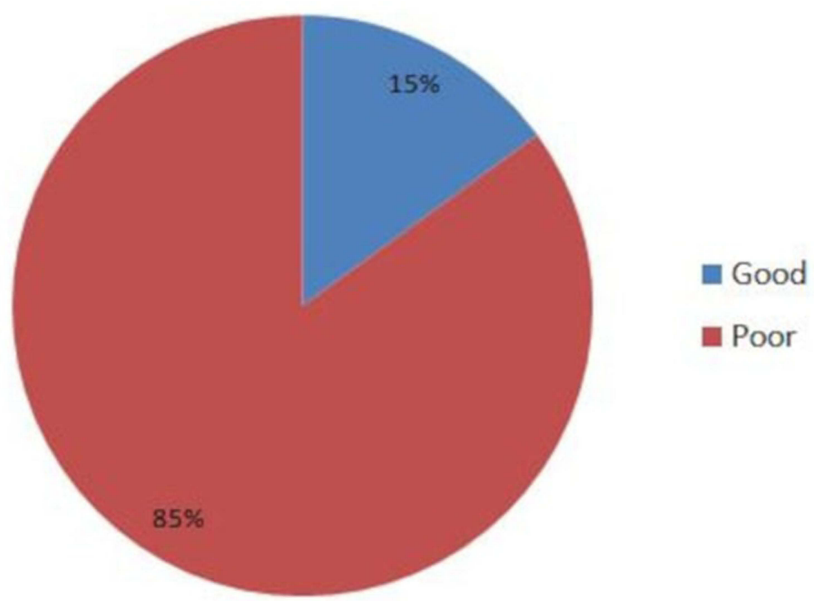

Figure 2 Knowledge of respondents on stroke warning signs at South Gondar Zone Comprehensive Specialized Hospital, Northwest Ethiopia, from June I-30, $2020(n=253)$. 
Table 5 Factors Associated with Stroke Knowledge on Warning Signs at South Gondar Zone Comprehensive Specialized Hospital, Northwest Ethiopia, from June I-30, $2020(n=253)$

\begin{tabular}{|c|c|c|c|c|c|c|}
\hline \multirow[t]{2}{*}{ Variables } & \multirow[t]{2}{*}{ Category } & \multicolumn{2}{|c|}{$\begin{array}{c}\text { Knowledge of Stroke } \\
\text { Warning Signs }\end{array}$} & \multirow[t]{2}{*}{ COR (95\% Cl) } & \multirow[t]{2}{*}{ AOR $(95 \% \mathrm{Cl})$} & \multirow[t]{2}{*}{ P-value } \\
\hline & & Good & Poor & & & \\
\hline Age & $\begin{array}{l}<45 \\
>45\end{array}$ & $\begin{array}{l}11 \\
27\end{array}$ & $\begin{array}{c}33 \\
182\end{array}$ & $\begin{array}{c}2.25(1.02-4.97) \\
1\end{array}$ & $\begin{array}{c}2.82(1.18-6.74) \\
I\end{array}$ & $0.02 *$ \\
\hline Residence & $\begin{array}{l}\text { Urban } \\
\text { Rural }\end{array}$ & $\begin{array}{c}33 \\
5\end{array}$ & $\begin{array}{l}134 \\
81\end{array}$ & $\begin{array}{c}3.99(1.497-10.63) \\
I\end{array}$ & $\begin{array}{c}2.9(1.04-8.11) \\
I\end{array}$ & $0.042^{*}$ \\
\hline Educational status & $\begin{array}{c}\text { Unable to read } \\
\text { \& write } \\
\text { Educated }\end{array}$ & $\begin{array}{c}8 \\
30\end{array}$ & $\begin{array}{l}102 \\
113\end{array}$ & $\begin{array}{c}\mathrm{I} \\
3.39(1.48-7.72)\end{array}$ & $\begin{array}{c}1 \\
2.6(1.09-6.23)\end{array}$ & $0.031 *$ \\
\hline Duration of hypertension & $\begin{array}{l}<5 \text { years } \\
>5 \text { years }\end{array}$ & $\begin{array}{l}20 \\
18\end{array}$ & $\begin{array}{r}|5| \\
64\end{array}$ & $\frac{1}{2.12(1.05-4.28)}$ & $\begin{array}{c}\mathrm{I} \\
2.7(1.25-5.8 I)\end{array}$ & $0.011 *$ \\
\hline Family history of stroke & $\begin{array}{l}\text { Yes } \\
\text { No }\end{array}$ & $\begin{array}{c}5 \\
33\end{array}$ & $\begin{array}{c}14 \\
201\end{array}$ & $\begin{array}{c}2.18(0.74-6.44) \\
1\end{array}$ & & \\
\hline Living with HIV/AIDS & $\begin{array}{l}\text { Yes } \\
\text { No }\end{array}$ & $\begin{array}{l}10 \\
28\end{array}$ & $\begin{array}{c}34 \\
|8|\end{array}$ & $\begin{array}{c}1.9(0.85-4.27) \\
\text { I }\end{array}$ & & \\
\hline Alcoholism & $\begin{array}{l}\text { Yes } \\
\text { No }\end{array}$ & $\begin{array}{l}13 \\
25\end{array}$ & $\begin{array}{c}49 \\
166\end{array}$ & $1.76(0.84-3.70)$ & & \\
\hline
\end{tabular}

Notes: I, reference group, *statistically significant.

\section{Limitations of the Study}

One of the limitations of this study was lack of causal association since the study was cross-sectional. In addition the study used non-standardized close-ended questions, which might limit the participants' responses for their knowledge. Furthermore, the study might not be representative of the community's knowledge since it was an institutional-based study.

\section{Conclusions}

The study showed that hypertensive patients' knowledge on stroke warning signs was poor. Being a young age, urban residence, being educated and long duration of hypertension follow up were the predictors of good stroke warning signs knowledge. Among those stroke warning signs sudden difficulty in swallowing $(80.6 \%)$ was the commonest one indicated by the participants.

This finding provides a good opportunity for hypertensive patients to obtain appropriate intervention based on the problems identified in the study and it will serve as baseline information for health-care workers to determine knowledge of their clients about stroke warning signs. Furthermore, it will show the magnitude of the problem for governmental and non-governmental organizations and it has a great role to give baseline information for researchers who intend to conduct further studies.

\section{Abbreviations}

AIDS, Acquired Immune Deficiency Syndrome; AOR, Adjusted Odds Ratio; CI, Confidence Interval; COR, Crude Odds Ratio; DM, Diabetes Mellitus; ETB, Ethiopian Birr; HIV, Human Immune Virus; HTN, Hypertension; SD, Standard Deviation; SGZCSH, South Gondar Zone Comprehensive Specialized Hospital; WHO, World Health Organization.

\section{Data Sharing Statement}

Data will be available upon request from the corresponding author.

\section{Ethical Approval and Consent to Participate}

Ethical clearance was obtained from the College of Medicine and Health Science's Ethical Review Board on behalf of Wollo University. Verbal consent was obtained from all study participants before the interview. The verbal informed consent was acceptable and approved by the Ethical review board on the behalf of Wollo University 
and this study was conducted under the Declaration of Helsinki. A formal letter of cooperation was written to South Gondar Zone Comprehensive Specialized Hospital administrative office from Wollo University and permission was obtained from the hospital administrative office. Study participants were informed about the purpose and their right to refuse the study.

\section{Acknowledgments}

The authors would like to thank the University for its financial support. Besides, we want to acknowledge data collectors and supervisors for their commitment to collect the data accurately.

\section{Author Contributions}

All authors made substantial contributions to conception, design, acquisition of data, or analysis and interpretation of data and took part in drafting the article or revising it critically for important intellectual content; agreed to submit to the current journal; gave final approval of the version to be published, and agree to be accountable for all aspects of the work. All authors have read and approved the final manuscript.

\section{Funding}

This research did not receive any grant from any funding agency in the public, commercial, or not-for-profit sectors.

\section{Disclosure}

The authors report no conflicts of interest in this work.

\section{References}

1. Walter Johnson a, Oyere Onuma b MO c \& SS a. WHO _ Stroke_ a global response is needed; 2016 [cited 2019 Nov 23.]. p. 633-708. Available from: file:///E:/Reference2/WHO_Stroke_aglobalresponseis needed.html. Accessed November 8, 2021.

2. Rashid M. Assessment of hypertensive patients knowledge about lifestyle risk factors and warning signs of stroke. J Contemp Med Sci. 2016;2(5):28-32.
3. Abbott H, Sim F. Unit: Public Health Aspects of Stroke Workbook. 3rd ed. Lorraine Williams and Fiona Sim: London; 2010:1-33 p

4. Mcmanus M, Liebeskind DS. Blood Pressure in Acute Ischemic Stroke. J Clin Neurol. 2016;12(2):137-146. doi:10.3988/ jcn.2016.12.2.137

5. Olin BR, Pharm D. Hypertension: the Silent Killer: updated JNC-8 Guideline Recommendations. Alabama Pharmacy Association. 2018:4222.

6. Yoon SS, Heller RF, Levi C, Wiggers J, Fitzgerald PE. Knowledge of Stroke Risk Factors, Warning Symptoms, and Treatment Among an Australian Urban Population. Stroke. 2015;1926-1931.

7. Dar NZ, Khan SA, Ahmad A, Maqsood S. Awareness of Stroke and Health-seeking Practices among Hypertensive Patients in a Tertiary Care Hospital: a Cross-sectional Survey. Cureus. 2019. doi:10.7759/ cureus. 4774

8. Ozkan S, Ata N. Stroke awareness in people with hypertension. Stroke. 2019;8(3):651-654.

9. Sulochana G, Shrestha Shakti LT. Factors Influencing Stroke Awareness among Patients with Hypertension in a Tertiary Hospital of Nepal_ A Cross-sectional Study (P6. 2018;(November 2019). Neurology. 2018;10:90.

10. Arisegi SA, Awosan KJ, Oche MO, Sabir AA, Ibrahim MT. Knowledge and practices related to stroke prevention among hypertensive and diabetic patients attending specialist hospital, Sokoto, Nigeria. Pan Afr Med J. 2018;29:1-17. doi:10.11604/ pamj.2018.29.63.13252

11. Ehidiamen OF, Ehinwenma OJ. Awareness of Stroke Risk Factors and Warning Symptoms amongst Hypertensive Patients in Benin City. Ann Med Health Sci Res. 2018;8(1):40-44.

12. Al-beladi BA, Al-oufi KM, Alhazmi AM, Nafea RM, Ibrahim HM. Awareness of Stroke among Diabetic and Hypertensive Patients at King Fahad Hospital in Al-Madinah, KSA, 2016. Int J Med Res Profes. 2018;4(4):2-6.

13. Abate AT, Bayu N, Mariam TG. Hypertensive Patients' Knowledge of Risk Factors and Warning Signs of Stroke at Felege Hiwot Referral Hospital, Northwest Ethiopia: a Cross-Sectional Study. Neurol Res Int. 2019;2019:215.

14. Dasgupta A, Sembiah S, Paul B, et al. Assessment of self-care practices among hypertensive patients: a clinic based study in rural area of Singur. West Bengal. 2018;5(1):262-267.

15. Tibebu NS, Emiru TD, Tiruneh CM, Nigat AB, Abate MW, Demelash AT. Knowledge on prevention of stroke and its associated factors among hypertensive patients at Debre Tabor general hospital: an institution-based cross-sectional study. Risk Manag Healthc Policy. 2021;14:1681-1688. doi:10.2147/RMHP.S303876

16. Soto-Cámara R, González-Bernal JJ, González-Santos J, AguilarParra JM, Trigueros R, López-Liria R. Knowledge on Signs and Risk Factors in Stroke Patients. J Clin Med. 2020;9(8):2557. doi: $10.3390 /$ jcm 9082557
Vascular Health and Risk Management

\section{Publish your work in this journal}

Vascular Health and Risk Management is an international, peerreviewed journal of therapeutics and risk management, focusing on concise rapid reporting of clinical studies on the processes involved in the maintenance of vascular health; the monitoring, prevention and treatment of vascular disease and its sequelae; and the involvement

\section{Dovepress}

of metabolic disorders, particularly diabetes. This journal is indexed on PubMed Central and MedLine. The manuscript management system is completely online and includes a very quick and fair peerreview system, which is all easy to use. Visit http://www.dovepress. com/testimonials.php to read real quotes from published authors. 